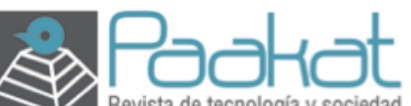

Paakat: Revista de Tecnología y Sociedad

e-ISSN: 2007-3607

Universidad de Guadalajara

Sistema de Universidad Virtual

México

suv.paakat@redudg.udg.mx

Año 10, número 18, marzo-agosto 2020

\title{
Uma rede sociotécnica à luz do paradigma da dádiva: análise do aplicativo de empréstimo de objetos Tem Açúcar? no Rio de Janeiro
}

\author{
A sociotechnical network in the light of the gift paradigm: \\ analysis of the object loan app Tem Açúcar? in Rio de Janeiro
}

\section{Una red sociotécnica a la luz del paradigma del don: análisis de la aplicación de préstamos de objetos Tem Açúcar? en Río de Janeiro}

\author{
Natalia da Silva Caldas Brito* \\ http://orcid.org/0000-0003-1130-4563 \\ Fundação Getulio Vargas, Brasil \\ Marisol Rodriguez Goia** \\ http://orcid.org/0000-0001-8733-7885 \\ Fundação Getulio Vargas, Brasil
}

[Recibido 11/11/2019. Aceptado para su publicación 26/02/2020]

DOI: http://dx.doi.org/10.32870/Pk.a10n18.472

\section{Resumo}

Este artigo realiza uma análise socioantropológica do Tem Açúcar?, um aplicativo criado em nome do consumo colaborativo, destinado a empréstimos, doações e troca de objetos entre vizinhos das grandes cidades. Situando a discussão no contexto das novas mobilizações coletivas organizadas em nome da solidariedade, adere-se à proposta de utilizar o marco interpretativo da dádiva, herdado da escola socioantropológica francesa, para uma melhor compreensão do fenómeno. Busca-se compreender as experiências e percepções de seus usuários e refletir sobre os aspectos que potencializam e limitam o propósito dessa rede sociotécnica no Rio de Janeiro, Brasil. Adota-se a fenomenologia interpretativa, incluindo observação, interação e entrevistas com usuários para descrever e analisar a aderência aos valores centrais do aplicativo, o sentido atribuído aos tipos de objetos que circulam, a forma como ocorrem os encontros e o papel da 
confiança para a viabilidade da reciprocidade. Além de um forte compromisso com a causa da redução do consumo e do fomento da colaboração e confiança entre vizinhos, o princípio da dádiva é defendido nessas práticas, que devem ser entendidas sob um enfoque anti-utilitarista. Ao mesmo tempo, a confiança é essencial para a materialização das trocas e sua construção depende da avaliação social do usuário, sua reputação e comentários em seu perfil.

\title{
Palavras-chave
}

Aplicativo de telecomunicação; dádiva; consumo colaborativo; solidariedade.

\begin{abstract}
This paper carries out a socio-anthropological analysis of Tem Açúcar?, a mobile application created in the name of collaborative consumption, intended for objects loans, donations and exchanges between neighbors of large cities. Placing the discussion in the context of the new collective mobilizations organized in the name of solidarity, it adheres to the interpretative framework of the gift, inherited from the French socio-anthropological school, for a better understanding of the phenomenon. It seeks to understand the experiences and perceptions of its users and reflects on the aspects that enhance and limit the purpose of this socio-technical network in Rio de Janeiro. Interpretative phenomenology is adopted, including observation, interaction and interviews with users to describe and analyze the adherence to the app values, the types of objects that circulate, the way in which encounters occur and the role of trust in the viability of reciprocity relationships. In addition to a strong commitment to the cause of reducing the consumption and the promotion of collaboration and trust among neighbors, the principle of the gift was verified in this sociotechnical network in practices that can only be understood under an anti-utilitarian approach. At the same time, trust is an essential factor for the materialization of exchanges and its construction depends on the reputation of the user, as well as the comments of third parties on their profile.
\end{abstract}

\section{Keywords}

Telecommunications applications; gift, collaborative consumption, solidarity.

\section{Resumen}

Este artículo realiza un análisis socioantropológico de Tem Açúcar?, una aplicación tecnológica creada en nombre del consumo colaborativo, destinada a préstamos, donaciones e intercambios de objetos entre vecinos de grandes ciudades. Ubicando la discusión en la coyuntura de las nuevas movilizaciones colectivas organizadas en nombre de la solidaridad, se adhiere a la propuesta de utilizar el marco interpretativo del don, heredado de la escuela socioantropológica francesa, para una mejor comprensión del fenómeno. Se busca comprender las experiencias y percepciones de sus usuarios, y reflexionar sobre los aspectos que potencian y limitan el propósito de esta red sociotécnica en Río de Janeiro, Brasil. Se adopta la fenomenología interpretativa, incluyendo observación, interacción y entrevistas con usuarios para describir y analizar la adherencia a los valores centrales de la aplicación, el sentido atribuido a los tipos de objetos que circulan, la forma en que ocurren los encuentros y el papel de la confianza para la viabilidad de la reciprocidad. Además de un fuerte compromiso con la causa de reducción del consumo y del fomento de la colaboración y confianza entre vecinos, el principio del don es defendido en estas prácticas, que deben entenderse bajo un enfoque anti-utilitarista. Al mismo tiempo, la confianza es esencial para la materialización de los intercambios y su construcción depende de la evaluación social del usuario, su reputación y comentarios en su perfil.

Palabras clave

Aplicación de telecomunicación; don; consumo colaborativo; solidaridad.

\section{Introdução}

Desde princípios do século $\mathrm{XX}$, o pensamento social se deteve sobre os efeitos sociais do acelerado processo de urbanização, advindo da industrialização e do 
capitalismo no mundo moderno. Autores clássicos do que se convenciona chamar de Sociologia e Antropologia Urbanas, como Georg Simmel, Louis Wirth, Robert Park, e pesquisadores da Escola de Chicago, recorreram a paradigmas sociais da vida no campo, ou em pequenos agrupamentos tradicionais, para enxergar, por contraste, as bruscas mudanças produzidas nas (e pelas) metrópoles. O urbano passou a ser pensado como um modo de vida, onde as identidades se tornam segmentadas, as relações face-a-face dão lugar a relações indiretas e anônimas, os valores individualistas e utilitários predominam sobre os valores comunais, as trocas são mediadas pelo dinheiro e, enfim, uma nova sensibilidade, marcada por uma atitude blasé diante dos outros e da realidade, marcaria o modelo do homem moderno das grandes metrópoles (Simmel, 1903; Park, 1915; Wirth, 1938).

No século XXI, as disruptivas inovações das tecnologias de informação e comunicação (Castells, 1999; 2003), não apenas permitiram que as críticas a esses princípios do ordenamento urbano-moderno ganhassem maior visibilidade, como também materializaram, elas mesmas, alguns processos de resistência e contestação (Tarrow, 2005; Anduiza et al., 2009; Castañeda, 2015; Soares et al., 2019). Plataformas digitais constituem, portanto, um cenário bastante promissor para a investigação da organização em rede movida em nome de valores contra-hegemônicos.

Embora pesquisas venham analisando o modo como valores contestatórios e ações políticas articulam pessoas por meio das tecnologias (Bennett \& Segerberg, 2011; Castañeda, 2015; Soares et al., 2019), ainda há um campo a ser desvendado no que se refere, especificamente, às práticas ligadas à resistência ao mainstream econômico e consumista, como as que fomentam, por meio de aplicativos gratuitos, doações e empréstimos de objetos entre desconhecidos nas grandes cidades.

É nesse contexto que se escolheu abordar o aplicativo de celular Tem Açúcar?, que se posiciona em nome do consumo consciente, da reconstituição dos laços comunitários e da preservação do meio-ambiente. Trata-se da plataforma de compartilhamento de bens mais difundida no Brasil, tendo alcançado mais de 180 mil usuários (Redbull, 2019). O aplicativo não tem fins lucrativos, opera atualmente em aproximadamente 10 mil municípios brasileiros e registra atividades em todos os estados do Brasil, seja em metrópoles como São Paulo e Rio de Janeiro, seja em cidades com menor densidade demográfica (Autossustentável, 2017).

Inspirado em plataformas de empréstimo, doação e troca de objetos, o Tem Açúcar? foi lançado no Brasil em junho de 2014 e se baseia na premissa de que "é melhor usar do que ter". Fundamentado em princípios de economia colaborativa e do consumo consciente, apresenta-se como mediador de relações de consumo, pela troca, empréstimo ou doação entre vizinhos. 
Adere-se, aqui, à proposta de usar o marco interpretativo da dádiva, herdado da escola sócio-antropológica francesa para o melhor entendimento dos usuários desse aplicativo (Godbout, 1998; Caillé, 1998; Martins, 2008). Os debates que articulam, contemporaneamente, o paradigma da dádiva ao desenvolvimento tecnológico, remetem ao consumo e à economia colaborativos (Heylighen, 2016; Harvey et al., 2014; Sutherland \& Jarrahi, 2018; Acquier \& Pinkse, 2017).

Ainda que se coloquem em relevo as contradições do conceito de economia colaborativa (Acquier \& Pinkse, 2017), uma de suas ideias fundantes merece ser posta em relevo como forma de posicionar o aplicativo no debate das redes sociais de resistência organizadas com a mediação das tecnologias. Trata-se do maior valor atribuído ao acesso do que à posse de bens, por meio de um sentido mais solidário na relação com objetos e serviços. Esse sentido conta com a mediação da tecnologia para se materializar em redes e comunidades de uso (Heylighen, 2016; Harvey et al., 2014).

Tal como vem sendo feito em pesquisas sobre tecnologia e experiência de usuários (Ghaffari \& Lagzian, 2018) este estudo adota uma abordagem fenomenológica interpretativa para buscar compreender e interpretar os usuários do Tem Açúcar? Após apresentar o aplicativo, retratando a motivação de sua idealizadora e sua dinâmica de funcionamento, discutem-se, com base em percepções e experiências, aspectos que potencializam e que limitam o propósito dessa rede sociotécnica (Latour, 2005) para a realização de empréstimos, doações e trocas de objetos entre desconhecidos de grandes centros urbanos.

Afim com a literatura sobre consumo e economia colaborativos, o tema da confiança merece um lugar especial na discussão (Acquier \& Pinkse, 2017; Heylighen, 2016; Sutherland \& Jarrahi, 2018), valor que se acentua quando se considera que a unidade de observação da pesquisa é a cidade do Rio de Janeiro, uma das mais desiguais e violentas do mundo.

Buscou-se conhecer e analisar questões objetivas e subjetivas sobre as interações que ocorrem por meio do aplicativo, tais como a adesão ao propósito do Tem Açúcar?, a forma como ocorrem os encontros, os tipos de objetos que circulam e o papel da confiança. Que aspectos operam favorável e desfavoravelmente para o propósito do aplicativo? De que modo pessoas e objetos são percebidos e avaliados? A esse respeito, busca-se atentar para a forma como o princípio da dádiva é reconhecido nessas interações. Por fim, nota-se o modo como, por meio do aplicativo, são estabelecidos laços sociais entre os seus usuários, para além da interação envolvendo os objetos. 


\section{As redes sociotécnicas e o paradigma da dádiva}

Em um dos trabalhos sociológicos pioneiros sobre as características do modelo de sociedade que emerge com o avanço das Tecnologias de Informação, Castells (1999) se refere às redes como as verdadeiras unidades operacionais da economia e da sociedade, merecedoras, portanto, de observação e análise. De fato, nas últimas décadas, os debates acadêmicos sobre a relação tecnologia e sociedade deram grande visibilidade ao modo como, por meio da tecnologia, são formadas redes de diferentes tipos e naturezas (Latour, 2005; Stalder, 2005; Bennett \& Segerberg, 2011; Castañeda, 2015; Heylighen, 2016; Soares et al., 2019).

A importância atribuída às redes torna cada vez mais importante o estudo dos dispositivos e desenvolvimentos tecnológicos, diante da sua capacidade de agir sobre a realidade, produzindo mudanças ou efeitos sobre a sociedade (Latour, 2005; Heylighen, 2016; Harvey et al., 2014; Soares et al., 2019). Tais dispositivos são entendidos por Latour (2005) como mediadores, como veículos que acionam outros mediadores e se orientam para a ação, tendo, portanto, poder de ação -diferentemente dos intermediários, que apenas transportam sem produzir efeitos-.

Interessado pela compreensão da organização contemporânea no modelo de redes horizontais, Martins (2010) pontua a necessidade de descolonizar os marcos interpretativos das Ciências Sociais para dar conta das motivações dos indivíduos pela associação e pela solidariedade, em novas formas de mobilizações coletivas. Estas motivações se materializam nas redes sociais, pequenos sistemas dinâmicos que funcionam como reguladores de acordos entre indivíduos e grupos, em nome da solidariedade (Harvey et al., 2014).

O paradigma utilitarista individualista, predominante na perspectiva das network analysis, seria insuficiente para compreender esses sistemas, já que os entende como formas de mobilização de recursos e informações em torno de objetivos estratégicos e interessados (Martins, 2010). Isto porque o sentido utilitarista de rede circunscreve a ação humana a partir de mecanismos de causalidades de ação, ancorando a moral dos comportamentos no cálculo e no interesse, sem ter "uma compreensão mais solidária, generosa e humanista do fenômeno" (Martins, 2010, p. 404). É para sanar essa lacuna que o autor defende o "paradigma da dádiva", herdado da escola sociológica francesa, como forma de entender novas formas de solidariedade articuladas em redes sociais que são, conforme Arnold-Chatalifaud, Thumala e Urquiza (2007), experiências inéditas de colaboração coletiva, fundadas na individualidade e na contingência.

Cabe dizer que a reflexão específica sobre a dádiva se liga à importância adquirida, no terreno da Antropologia, pela discussão da economia e das trocas nos povos tribais, ganhando visibilidade na década de 1920. Os estudos de Bronislaw Malinowski e de Marcel Mauss, com suas respectivas obras 
"Argonautas do Pacífico Ocidental", de 1922, e "Ensaio sobre a Dádiva", de 1925, são os marcos desse debate. Tais trabalhos evidenciaram a complexidade dos sistemas de troca nas sociedades tradicionais, sua relação com o ordenamento social e com os princípios que fundamentam os contratos estabelecidos entre grupos. O debate contribui, até hoje, para relativizar as modalidades ocidentais e "modernas" da Economia e do Direito.

Uma das principais contribuições é o reconhecimento que Mauss realiza de um princípio social subjacente a diferentes modalidades de troca. Trata-se do princípio de dar, receber e retribuir, que tem caráter simultaneamente obrigatório e voluntário e é estruturante das relações sociais. Muito embora Mauss reconhecesse diferenças entre as modalidades de troca nas sociedades tribais, ancoradas no princípio da dádiva, e aquelas da economia moderna, o autor se comprazia ao ampliar o que entendia como "sobrevivências" culturais tradicionais.

Entre a economia relativamente amorfa e desinteressada, no interior dos subgrupos, que regula a vida dos clãs australianos ou norte-americanos, de um lado, e de outro, a economia individual e do puro interesse que nossas sociedades conheceram, ao menos em parte, desde que essa economia foi descoberta pelas populações semíticas e gregas, entre esses dois tipos dispôsse uma série imensa de instituições e de acontecimentos econômicos, e essa série não é governada pelo racionalismo econômico do qual se costuma fazer a teoria (Mauss, 2003, p. 306).

O paradigma antropológico da dádiva considera que as dádivas (objetos, bens, serviços, etcetera) em circulação nutrem alianças e relações pelo endividamento positivo e mútuo entre as pessoas. Nesse sentido, os indivíduos são interdependentes e relacionados por meio de bens (as dádivas oferecidas) que circulam e que simbolizam o "espírito" do doador e seu grupo (Mauss, 2003).

Sob a leitura de Caillé (1998), Marcel Mauss teria indicado que o que é trocado -mais do que objetos, presentes, festas, braceletes- são símbolos. Símbolos da presença de grupos e símbolos das necessidades de cada membro e de todos. Símbolos das alianças e das necessidades de alianças. Mauss teria revelado que nenhuma sociedade humana pode edificar-se exclusivamente sobre o registro do contrato e do utilitário, insistindo, ao contrário, em que a solidariedade indispensável a qualquer ordem social só pode surgir da subordinação dos interesses materiais a uma regra simbólica capaz de transcendê-los. A "obrigação paradoxal da generosidade" constituiria, assim, a base dessa moralidade, uma moral que manda dar de modo livre e obrigatório, simultaneamente (Caillé, 1998).

É no seio dessa discussão que Martins (2010) defende as perspectivas sociológicas anti-utilitaristas, formadas ao longo do século $X X$, como desdobramentos da teoria da dádiva, como adequadas para a interpretação de 
fenômenos contemporâneos de mobilização solidária em rede. Tal paradigma insiste em valorizar a força da associação humana como um poderoso recurso explicativo dos movimentos coletivos e espontâneos, o que permite compreender formas de construção de esferas públicas democráticas a partir da sociedade civil, fora das esferas do Estado e do mercado.

\section{Tecnologia, práticas colaborativas e confiança}

Os debates que articulam, contemporaneamente, o paradigma da dádiva ao desenvolvimento tecnológico, remetem ao consumo e à economia colaborativos (Heylighen, 2016; Harvey et al., 2014; Sutherland \& Jarrahi, 2018; Acquier \& Pinkse, 2017).

A economia colaborativa é usualmente pensada como um modelo econômico construído ao redor de redes conectadas de indivíduos e comunidades (Sutherland \& Jarrahi, 2018; Botsman \& Rogers, 2011), entrando neste ponto a mediação ou a intermediação da tecnologia (Latour. 2005). Hamari et al. (2016) conceituam o consumo colaborativo como fenômeno essencialmente tecnológico, em que tanto a oferta quanto o uso de recursos se veem intimamente conectados por redes de pares, manifestando-se através da obtenção, doação ou partilha do acesso a bens e serviços por uma comunidade online.

Belk $(2010 ; 2014)$ aborda o consumo e a economia colaborativos como ação e processo de distribuição do que se possui, e também como ação e processo de recebimento de coisas de outras pessoas para uso. Como resultado, uma identidade também é compartilhada, seja entre vizinhos de prédio, bairro, cidade ou aplicativo, pelo senso de pertencimento e ainda, de solidariedade no consumo colaborativo (Belk, 2010; 2014).

Ainda que se coloquem em relevo as contradições do conceito de economia colaborativa (Acquier \& Pinkse, 2017), uma de suas ideias fundantes deve ser colocada em relevo. Trata-se do maior valor atribuído ao acesso do que à posse de bens, uma proposta de repensar o uso de objetos e serviços através de um modelo econômico organizado em redes e comunidades (Heylighen, 2016; Harvey et al., 2014). Nesse sentido, o campo de aplicação desse novo modelo é grande e leva em conta o conjunto de procedimentos de troca, de partilha ou empréstimo de recursos entre pessoas ou empresas (Sutherland \& Jarrahi, 2018).

No que se refere à relação entre dádiva e tecnologia, deve-se mencionar a noção da dádiva high-tech, que se desenvolveu no contexto do compartilhamento de arquivos via online e no movimento de software livre (Barbrook, 1998; Stalder, 2005). Essa corrente se caracteriza pela cooperação livre entre produtores e consumidores de conteúdo, associados sem que haja espera por contrapartida monetária (Harvey et al., 2014). O reconhecimento, 
nesse caso, passa pela identificação de talentos e méritos dos pares, de maneira igualitária. É possível compreender essa cultura (Stadler, 2005) como uma combinação entre coletivismo e individualismo, na qual a capacidade de doar é, precisamente, o que torna o indivíduo um virtuoso aos olhos de seus pares (Bergquist \& Ljungberg, 2001).

O conceito de confiança é central nos debates sobre paradigmas de trocas mediadas por plataformas digitais. A ligação direta entre pares é feita por um terceiro que, sem tomar parte na troca, serve de mediador (Heylighen, 2016). Nos debates sobre trocas monetizadas mediadas por dispositivos, argumentase que a relação entre consumidor e empresa é substituída por uma relação tripla, na qual um dispositivo faz um papel de intermediário na transação. Nesse sentido, as plataformas normalmente apostam na reputação pessoal e buscam estabelecer a posição de elemento que garante a transação, resolvendo a questão da incerteza e promovendo o engajamento na relação por meio da plataforma (Möhlmann, 2015; Sundararajan, 2016).

A fim de construir confiança suficiente, plataformas colaborativas têm como opção reforçar a confiança na organização, de modo a facilitar a transferência desse valor em direção a terceiros (Sundararajan, 2016). As plataformas oferecem ferramentas que permitem aos usuários mais reticentes validar elementos que certifiquem a segurança no procedimento.

Segundo Botsman e Rogers (2011), a confiança é o principal elemento da economia colaborativa. Um dos principais desafios de manter práticas e modelos colaborativos em funcionamento é, portanto, desenvolver e manter a confiança em plataformas digitais e, por meio delas, também nos seus usuários.

\section{Metodologia}

Entende-se, com Martins (2010), que as abordagens interpretativas fenomenológicas são pertinentes para avançar no debate sobre as redes sociais mediadas por dispositivos tecnológicos porque permitem colocar em relevo as percepções da realidade humana, as linguagens e as narrativas que tecem significações para a vida social. De fato, como se pode notar na literatura internacional, a adoção da abordagem fenomenológica vem crescendo na produção científica especializada em tecnologia e experiência (Ghaffari \& Lagzian, 2018; Symeonides \& Carrie, 2015; Saraswat 2012; Galehbakhtiari \& Tahmours, 2015; Chan et al., 2015).

A fenomenologia interpretativa encoraja os pesquisadores a elucidarem o modo como os participantes criam um sentido para seus mundos pessoais e sociais e dão significado a suas experiências (Madsbjerg, 2017). Em termos ontológicos, a fenomenologia pressupõe uma integração entre o fenômeno 
estudado e o observador, ocupando a intenção do pesquisador um importante papel na criação de conhecimento, assim como nas implicações de seu estudo (Smith, 2004).

Com base fenomenológica, a metodologia desta pesquisa é qualitativa, descritiva e exploratória, construída a partir da inscrição direta de uma das autoras no universo pesquisado, por meio de observações do próprio aplicativo, interações com a plataforma e com seus usuários, e por meio de entrevistas semiestruturadas realizadas presencialmente e remotamente com seus usuários. Não se pretende generalizar os depoimentos e experiências observados para a totalidade de usuários do Tem Açúcar?, mas sim, tomá-los como pontos de inflexão sobre o fenômeno da solidariedade sob roupagens contemporâneas, entendida como resistência ao utilitarismo, e mediada pela tecnologia.

Uma das seleções do público participante foi realizada pela própria plataforma do Tem Açúcar?, "pedindo uma mãozinha", ferramenta do aplicativo. A mensagem em tom coloquial, o mesmo tom de fala utilizado pelos usuários cadastrados, foi postada para visualização em um raio de $2,1 \mathrm{~km}$ de um endereço cadastrado no bairro de Botafogo, Rio de Janeiro, convidando-os a participarem da pesquisa.

Além desse convite, a segunda seleção do público participante, por motivo de conveniência, foi a escolha de um perfil de pessoas que tivessem curtido a página do Tem Açúcar? pela plataforma de rede social Facebook ou interagido pelo menos uma vez pelo aplicativo, seja solicitando algum objeto ou emprestando. Por fim, também foi possível acessar novos entrevistados a partir de indicações realizadas ao final de cada entrevista, conforme o método da "bola de neve".

Deste modo, foram realizadas, no total, 9 (nove) entrevistas semiestruturadas, sendo 6 (seis) presenciais e 3 (três) à distância que compartilharam suas experiências e percepções sobre o aplicativo Tem Açúcar?

As conversas e o roteiro das entrevistas giraram ao redor das experiências de uso do aplicativo, como impressões gerais, tempo de uso, critérios adotados para a avaliação de usuários, tipos de objetos que consideram aptos, ou não, a circular, entre outras. No início de cada encontro foi solicitado aos entrevistados que fizessem uma breve apresentação de seu próprio perfil, com informações de idade, escolaridade, ocupação, entre outras.

O perfil dos informantes foi de 7 mulheres e 2 homens, sendo 8 entre os 9 entrevistados com idade entre 30 e 40 anos, e 1 entrevistado com idade entre 20 e 30 anos. Pode-se dizer que a frequência de uso do aplicativo não é regular entre os usuários. A maior parte deles ativa as notificações do aplicativo em seu celular, consultando-as sempre que aparecem. Isto não 
significa que os usuários interajam diariamente com o aplicativo, nem que tomem parte das solicitações notificadas.

Além disso, mesmo a habilitação das notificações passa por intermitências. Ainda assim, nenhum entrevistado relatou menos de 3 trocas efetivadas e a maior parte deles narrou ter participado de empréstimos ou doações em diferentes ocasiões. Informações adicionais de profissão e bairro de moradia dos participantes da pesquisa se encontram na tabela abaixo.

Tabela 1. Perfil dos informantes

\begin{tabular}{|c|c|c|c|c|}
\hline Entrevistado & Idade & Sexo & Profissão & Moradia \\
\hline A & 34 & F & Designer & Catete \\
\hline B & 37 & F & Designer & Botafogo \\
\hline C & 34 & F & Pedagoga & Bairro de Fátima \\
\hline D & 35 & F & Empreendedora & Barra da Tijuca \\
\hline E & 24 & F & Publicitária & Leblon \\
\hline F & 38 & F & Empreendedora & Glória \\
\hline G & 35 & M & Publicitário & Barra da Tijuca \\
\hline H & 32 & M & Administrador & Flamengo \\
\hline I & 36 & F & Designer & Icaraí \\
\hline
\end{tabular}

Fonte: elaboração própria.

\section{Contextualizando o aplicativo Tem Açúcar?}

Eu enxergo a economia de compartilhamento como um processo inteligente, divertido, natural e necessário para um planeta que tem recursos finitos. Para a criação de novos bens, recursos naturais são extraídos de forma não renovável, gasta-se energia com transporte e produção, lixo é gerado e isso impacta socialmente trabalhadores que ganham cada vez menos -ou muitas vezes nada, o trabalho escravo- para dar conta de uma demanda sempre crescente

Camila Carvalho - Hypeness, 2015

A história do Tem Açúcar? nasce de um incômodo sentido por Camila Carvalho, nascida em 1989, ex-modelo, natural do Rio de Janeiro e fundadora da plataforma. Antes de se tornar empreendedora social, foi estudante de Comunicação Social e Artes Cênicas, para depois ingressar na carreira de modelo e trabalhar para grandes marcas do mercado da moda. Em viagens por 
países como Índia e China, Camila teve contato com a diversidade cultural e especialmente com uma visível desigualdade social entre ocidente e oriente.

O impacto de ter vivido e convivido com essa desigualdade impulsionou suas reflexões sobre o modo de funcionamento do capitalismo de consumo e especialmente as dinâmicas de poder, produção industrial, política e impactos ambientais. A expansão de consciência sobre os efeitos da economia de mercado motivou o interesse em estudar Design em Sustentabilidade pela instituição internacional Gaia Education, e posteriormente, a criação da plataforma em questão.

Outro elemento motivador para a criação do Tem Açúcar? foi a percepção de que as relações de vizinhança nas metrópoles são pouco sólidas. Essa mesma percepção havia sido fundamental para a criação de plataformas internacionais que foram fonte de estudo e referências para o Tem Açúcar?, como a holandesa Peerby e a inglesa Streetbank (O Globo, 2015).

Depois de passar por uma campanha de financiamento coletivo (matchfunding) em outubro de 2016, o Tem Açúcar? se transformou em aplicativo para smartphones e se tornou mais acessível e responsivo. A campanha contou com o apoio da empresa seguradora Youse e também com a contribuição individual de 395 pessoas, tendo arrecadado $\mathrm{R} \$ 61.562,00$ (sessenta e um mil, quinhentos e sessenta e dois reais). Em 2020, a plataforma de troca opera exclusivamente como aplicativo, possuindo um total de $180 \mathrm{mil}$ usuários (Redbul, 2019).

Para fazer uso do Tem Açúcar? o usuário deve baixar o aplicativo, disponível gratuitamente no Google Play ou na Apple Store (conforme o tipo de aparelho celular) e se cadastrar (figura 1).

Na página principal do aplicativo o usuário pode descobrir quantos vizinhos na sua área estão cadastrados e assim ter uma ideia do universo de trocas possíveis e quais foram os pedidos mais recentes efetuados pela comunidade no seu entorno. Ainda sobre funcionalidades, dentro do aplicativo é também possível se associar a comunidades específicas, direcionadas a públicos particulares (comunidades de mães e pais, comunidades de compras coletivas, etcetera), para que o usuário se mantenha mais integrado ao que acontece nas redondezas.

Após a realização do login, o usuário pode selecionar através do Editar Perfil o endereço onde deseja consultar vizinhos e quantos são os vizinhos disponíveis no endereço cadastrado. As figuras 2 e 3 mostram o exemplo de dois endereços diferentes, o primeiro com 1298 usuários cadastrados no bairro de Botafogo, da cidade do Rio de Janeiro, e o segundo com 468 usuários disponíveis no bairro de Santa Rosa, na cidade de Niterói, próxima à cidade do Rio de Janeiro. 


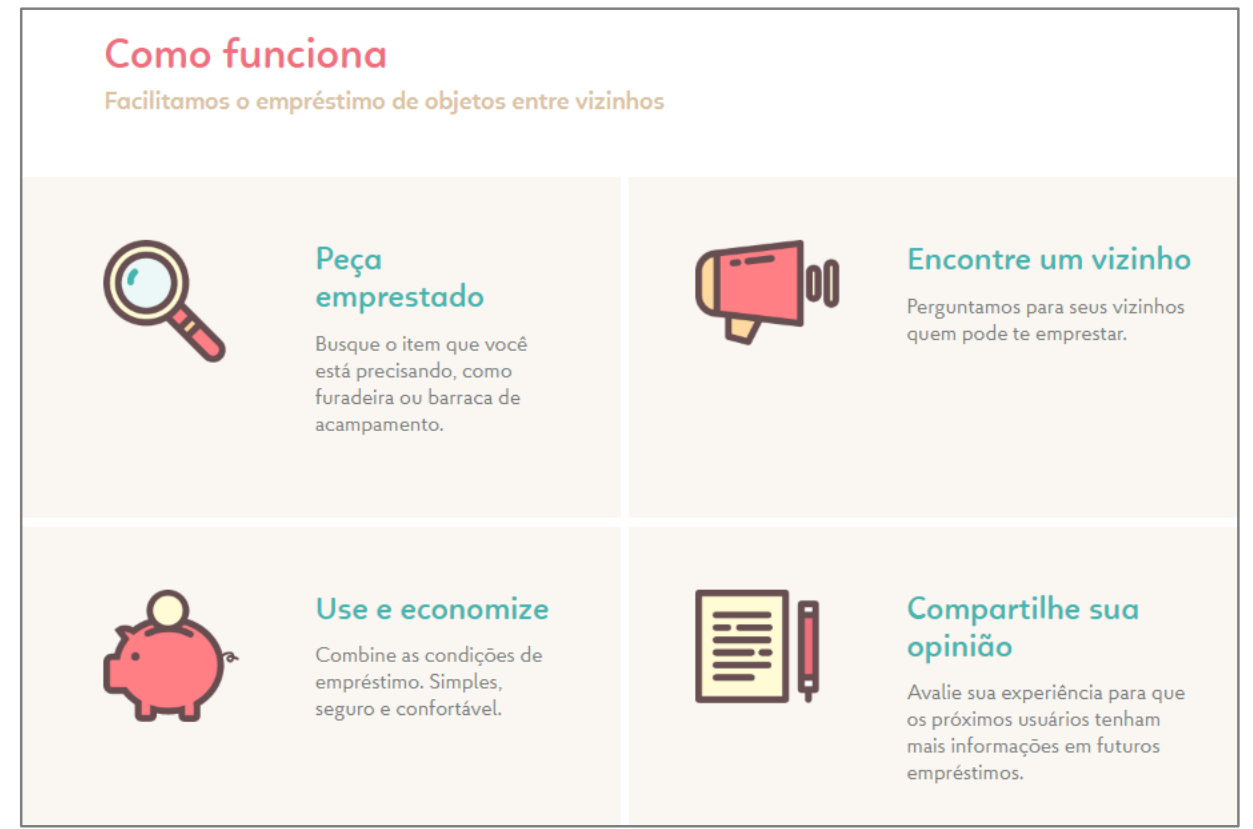

Figura 1. Funcionamento do aplicativo. Fonte: Aplicativo Tem açúcar?

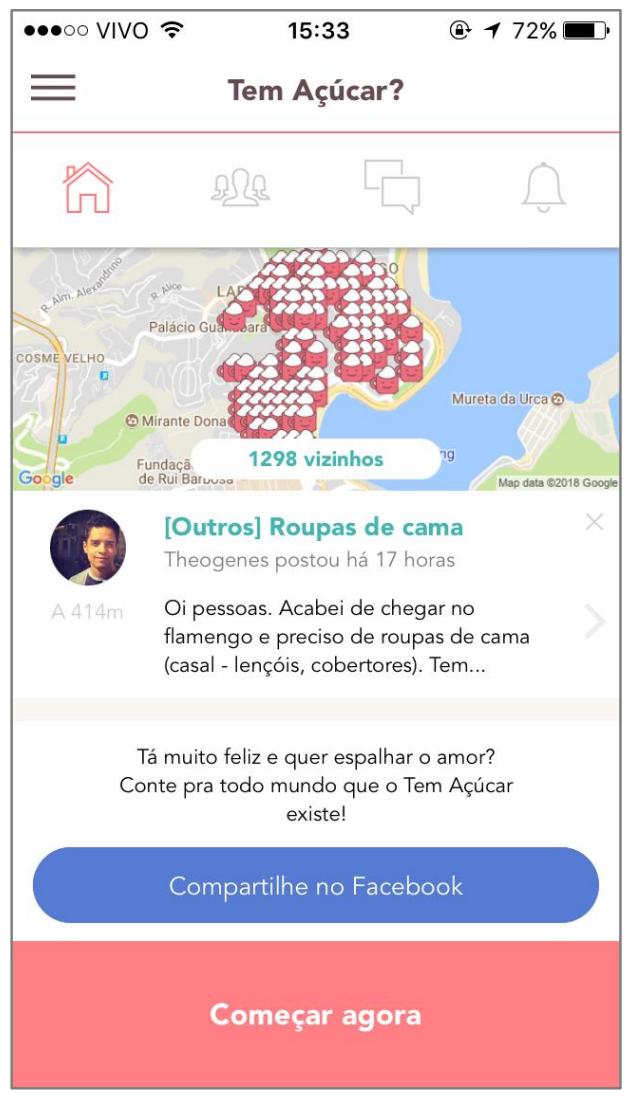

Figura 2. Home - Quantidade de vizinhos cadastrados - Bairro Botafogo. Fonte: Aplicativo Tem Açúcar? 


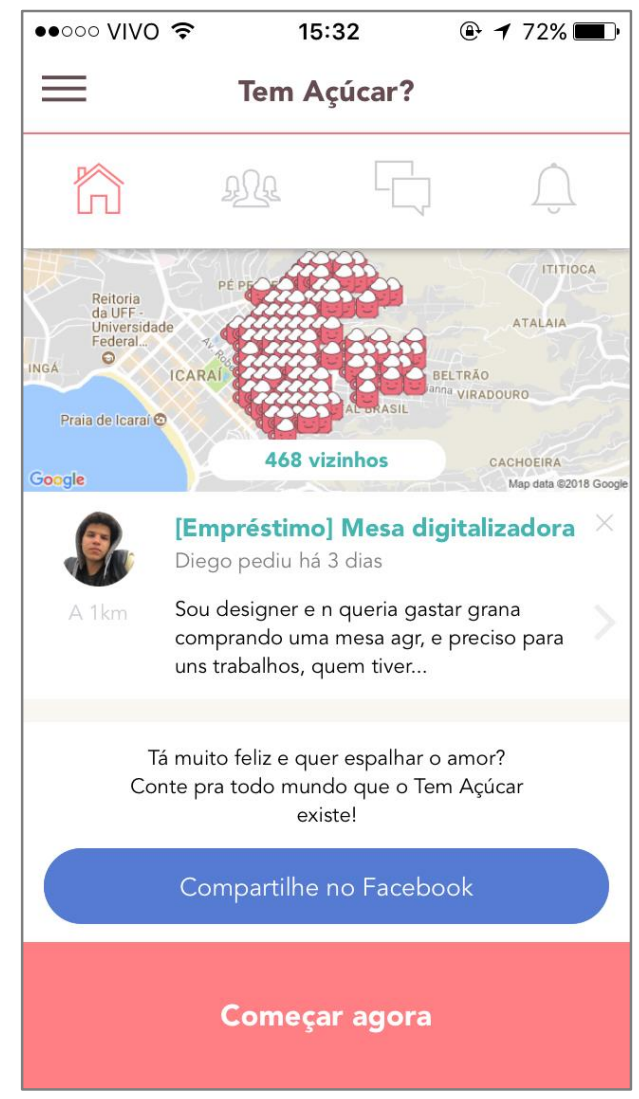

Figura 3. Home - Quantidade de vizinhos - Bairro Vital Brazil. Fonte: Aplicativo Tem Açúcar?

As possibilidades de interação são variadas. É possível encontrar pedidos de empréstimo de objetos, como por exemplo mochilão para viagem, barraca de camping, projetor de vídeo para casamento, furadeira, livros para estudos ou então pedidos de ajuda para montagem de armário, companhia para atividades físicas como corrida, até doações de livros ou comidas, por exemplo papinhas de crianças (figura 4 ).

Durante todo o processo de produção da presente pesquisa, observaramse diversas postagens com pedidos variados dentro do aplicativo, desde doação de composteiras ou camas, até empréstimo de itens pessoais tais como tênis, livros, lentes fotográficas, mochilas, panelas, kefir, furadeiras e ainda pedidos de troca de informações. Diante dessa variedade, é preciso admitir a impossibilidade de afirmar com precisão quais itens são mais demandados através da plataforma, pois o aplicativo não permite o acesso a esses dados. 


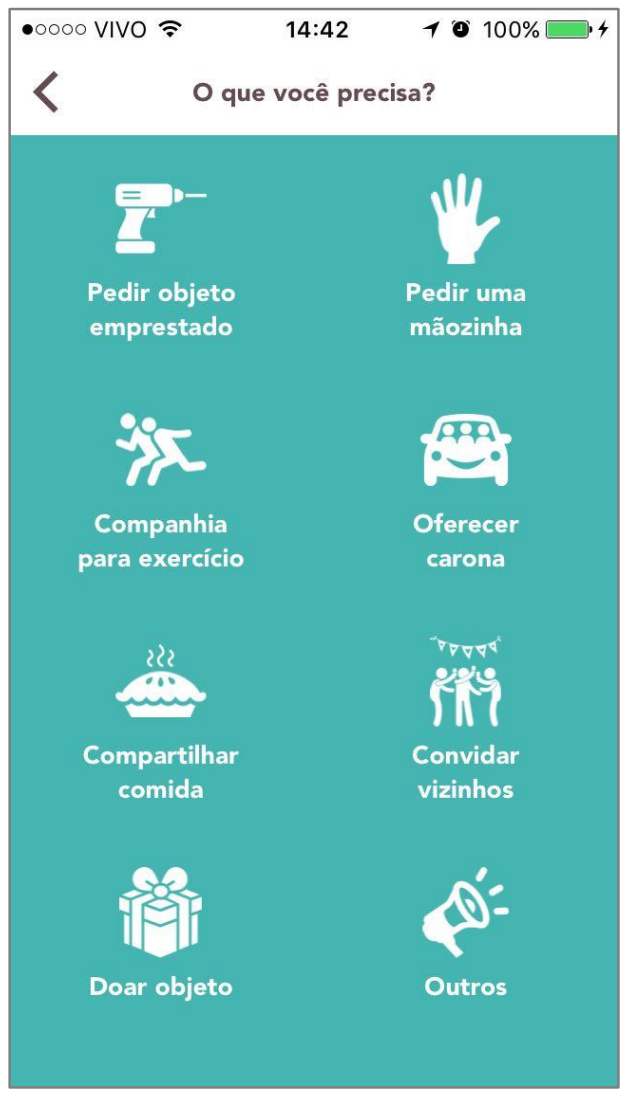

Figura 4. Tipos de interação.

Fonte: Aplicativo Tem Açúcar?

\section{Resultados}

\section{Experiências e percepções dos usuários}

Quando perguntadas sobre como foram as experiências com o aplicativo, pôdese notar algumas tendências interessantes nas respostas. A maioria das pessoas entrevistadas relatou êxito tanto na atividade de emprestar quanto na de pegar emprestado (ou receber algo como doação), tendo duas ou mais experiências de troca, com usuários diferentes e também repetidos. Entretanto, revelou-se que 3/9 das pessoas entrevistadas vivenciou também dificuldades em obter respostas para seus pedidos e acabaram, de alguma forma, frustrados.

Por outro lado, 2/9 dos usuários relatou não ter conseguido concluir trocas, seja por dificuldade de alinhamento para o encontro presencial, seja por motivos outros (como desistência da outra parte).

Pedir emprestado eu só tentei uma vez, só que eu não obtive resposta. Se não me engano era um daqueles quadros de música pra pendurar partitura. Então na época eu tinha uma amiga que ia fazer um show e ela precisava desse objeto. 
Eu coloquei lá no aplicativo e eu não obtive resposta, mas tudo bem (entrevistado $\mathrm{H}, 32$, Administrador, Flamengo).

Outra tendência entre as pessoas entrevistadas foi a intermitência no uso do aplicativo, isto é, muitos afirmaram terem, em algum momento, desinstalado o Tem Açúcar?, seja por desmotivação (gerada pelo não atingimento de uma expectativa), seja por terem feito apenas um uso pontual do mesmo.

As entrevistas revelaram experiências e preferências bem claras. A maioria classificou o processo de alinhamento, agendamento e troca como tranquilos. Todos confirmaram jornadas de troca que começaram no aplicativo e se concretizaram quando a comunicação migrou para fora do Tem Açúcar?, no caso, o Whatsapp.

Foi tranquilo. Eu já tinha pego também o telefone do Whatsapp, que a gente tinha vários assuntos em comum de designer. E até troquei uma ideia para ver se ele podia me indicar alguns clientes, que ele trabalhava numa empresa. E aí eu fiquei com o telefone dele pessoal, e acabou que comecei a tratar tudo pelo Whatsapp, e não pelo aplicativo. Foi mais fácil (entrevistada I, 36, Designer, Icaraí).

Outra tendência entre os usuários é o agendamento da troca em um local público, normalmente nas proximidades da residência de quem está doando ou emprestando, ou ainda a prática de deixar ou buscar o objeto desejado na portaria de quem o está cedendo. Importante notar que, na maior parte das vezes, a troca acontece presencialmente, e o encontro poucas vezes se dá na casa de quem empresta ou doa.

A gente marcou o dia, e essa mora bem mais perto de mim, ela mora no Centro também. A gente marcou um dia, passei na portaria, ela tava passeando com o cachorro e eu digo: "ah, tá aqui". Pegou, me entregou o skate e "oi, muito obrigada, tchau, smack smack e beijos" (entrevistada C, 34, Pedagoga, Bairro de Fátima).

A troca por meio de aplicativos depende de confiança. As entrevistas realizadas mostram que, nesse sentido, a maioria esmagadora dos usuários confiaram nas avaliações do aplicativo e se fiaram nelas para materializar a troca com a outra pessoa. Apenas uma das entrevistadas afirmou ter ido buscar mais informações, pesquisando sobre a pessoa no Facebook. Neste caso, verificar se há amigos em comum nessa rede social ajudou a atenuar a desconfiança:

Ah, olhei Facebook. É uma segurançazinha. Tinham amigos em comum, um era designer. Aí eu falei: "então tá tranquilo". Mas também marquei de encontrar na 
rua. Acho que é muito mais tranquilo do que receber em casa, que a gente ainda tem esse receio (entrevistada I, 36, Designer, Icaraí).

Além disso, quando perguntados se realizariam trocas com qualquer pessoa, 5/9 dos entrevistados disseram que não, afirmando que dependeriam dos comentários e avaliações no perfil da outra pessoa dentro do aplicativo Tem Açúcar? Nesse sentido, foi possível perceber o quanto usuários recentes e sem avaliação representam um risco maior e geram menos confiança para a transação. Esses usuários acabam tendo chances menores de êxito e dependem do desejo da outra pessoa em criar confiança a partir de conversas fora do aplicativo e busca de informações em redes sociais. A partir das respostas foi possível notar ainda a importância da proximidade geográfica e que este seria um fator impeditivo de troca com qualquer pessoa. Por outro lado, quatro pessoas disseram que não teriam qualquer limite e que trocariam com qualquer pessoa:

É, acho que sim. Agora que você me perguntou isso eu tô me achando um pouco inconsequente. Normalmente eu olho só as avaliações da pessoa, só pra eu ver se ela... mas às vezes a pessoa também é nova, então não tem avaliação nenhuma. Então vai muito do papo que eu tô tendo com a pessoa também (entrevistada E, 24, Publicitária, Leblon).

Ah, se for muito longe, se não tiver nenhuma avaliação ou se tiver avaliações ruins ou se for alguma coisa assim... não sei. Eu acho que basicamente isso, que eu não sinta que posso confiar, entendeu? (entrevistada A, 34, Designer, Catete).

Conforme já mencionado, a confiança é um fator elementar para as trocas analisadas na presente pesquisa. Nesse sentido, as avaliações ganham peso relevante no aplicativo, pois manifestam a reputação de cada usuário. Assim, julgou-se relevante perguntar aos entrevistados o que consideram no momento de avaliar um usuário. As respostas revelaram que pontualidade, compromisso e disponibilidade para comunicação são os três elementos mais considerados. Foram citados também o zelo pelo objeto, a simpatia na abordagem e a honestidade:

Compromisso com a pessoa. Diz que vai devolver num prazo X. É o compromisso dela mesmo. Você tá fazendo algo bom, né. Mas você também espera que a pessoa possa pelo menos ter esse compromisso de devolver ou dar uma satisfação. Uma coisa que eu sempre tive pelo aplicativo. E o zelo também pelo seu objeto, né. Devolver da mesma forma que pegou emprestado. Acho que isso também é bem importante (entrevistado H, 32, Administrador, Flamengo).

Quando perguntados sobre o que achavam que outros usuários consideram quando avaliam, todos os entrevistados citaram os mesmos elementos mencionados acima. 
Quando perguntados se havia um limite do que emprestar, todos os 9 usuários entrevistados disseram que sim, afirmando que dificilmente emprestariam objetos pessoais, com valor afetivo e valores financeiros considerados altos e objetos de uso profissional ou frágeis. Isto é, não estariam dispostos a emprestar coisas pessoais insubstituíveis, emocional ou financeiramente. Ainda que todos os entrevistados afirmem que existe um limite do que emprestar, os objetos dados como exemplos possuem claramente pesos e valores diferentes, especialmente no que se refere àquilo que se chama de valor financeiro, conceito naturalmente relativo e subjetivo.

Bom, tem, tem limite. Mas eu não sei se... eu acho que as coisas que eu não emprestaria pelo aplicativo eu não emprestaria de jeito nenhum, sabe? Não sei, por exemplo, eu emprestei a lente da minha câmera. Eu não sei se eu emprestaria a câmera inteira, sabe? Mas eu também não sei se eu emprestaria ela para alguém que me pedisse normalmente, sem ser pelo aplicativo. E coisas mais pessoais. Por exemplo, quando emprestei a máquina do cartão. Eu tenho ela há pouco tempo e também não sabia usar. Sabe, eu fiquei um pouco insegura. Emprestei, mas fiquei um pouco insegura se tinha algum dado naquilo, sabe? Depois eu vi que não. A própria pessoa me explicou, me ajudou, me ensinou a mexer em outras coisas no aplicativo dela depois. Mas eu fiquei um pouco insegura. Então, assim, coisas que possam ter meus dados eu acho que eu não emprestaria (entrevistada B, 37, Designer, Botafogo).

Ah, por exemplo, uma pessoa tava pedindo objetos pra fazer uma festa mexicana, temática. Eu tenho uma caveira mexicana, mas a minha amiga trouxe, essa caveira mexicana é do México, sabe? Eu não vou emprestar porque pode quebrar, entendeu? Então assim, essas coisas muito emocionais ou de quebrar, aí não (entrevistada F, 38, Empreendedora, Glória).

Aproximadamente $7 / 9$ dos entrevistados relataram que sim, as trocas realizadas acabaram por gerar relacionamento externo, seja se tornando uma amizade de redes sociais (Facebook e Instagram foram os mais mencionados), seja se tornando um contato para dicas de viagem ou oportunidades profissionais, através de comunicação via Whatsapp. Mesmo que intermitentes ou ocasionais, foi possível notar que a maior parte das trocas acabaram de fato aproximando os usuários no "off-line", gerando assim uma proximidade maior entre vizinhos.

Ah sim, hoje a gente é amigo de rede social. A gente comenta às vezes stories no Instagram, acompanha viagem. Ele tava mês passado no Pará, achei legal. Pará não, no Norte do Brasil, né. E em outros lugares por lá também. E eu achei interessante a viagem dele, o roteiro que ele fez. Ele foi postando, aí se eu for para lá eu pego informações com ele (Entrevistada C, 34, Pedagoga, Bairro de Fátima). 
No que se refere aos relatos de reciprocidade, aproximadamente $3 / 9$ das pessoas entrevistadas receberam ou deram agradecimentos materiais no momento de receberem de volta, ou de devolverem um objeto, como um souvenir de viagem, um bolinho ou até mesmo um bilhetinho de agradecimento:

Eu precisei para uma viagem e eu não precisei comprar um mochilão. Aliás, eu prometi que traria um souvenir pro João, e trouxe (entrevistada C, 34, Pedagoga, Bairro de Fátima).

Foi uma surpresa muito boa, uma coisa que eu não esperava. Óbvio que eu esperava agradecimento, mas assim, eu não tinha imaginado que ia ser tão bonitinho, sabe? Foi quase receber um presente. Achei muito bom (entrevistada B, 37, Designer, Botafogo).

Aí quando eu recebi de volta, ela ainda me deu um bolinho lá de presente. Eu achei fofo e eu fiquei "ai, que bom que a gente consegue emprestar as coisas e sair um pouco da nossa zona de conforto mesmo (entrevistada E, 24, Publicitária, Leblon).

Finalmente, quando perguntados sobre a principal função, a principal entrega do aplicativo em questão, os entrevistados concordaram que o Tem Açúcar? ajuda a comprar menos e ao mesmo tempo facilita a aproximação das pessoas na vida real, promovendo, assim, um sentido de comunidade. Inserido em um contexto de economia colaborativa, entende-se que o aplicativo Tem Açúcar? atrai usuários alinhados com essa realidade. Revelou-se que os entrevistados são entusiastas da economia colaborativa, que a consideram relevante e fundamental para gerar impacto social positivo, além de promover um consumo mais consciente.

Eu acho que é essa união da comunidade, dos vizinhos, sabe? Eu acho que é trabalhar a confiança entre as pessoas. A gente não trabalha isso, né? Não pode confiar muito, não pode pedir ajuda para o outro, não pode contar com o outro. E a principal entrega [do aplicativo] pra mim seria essa, essa experiência (entrevistada F, 38, Empreendedora, Glória).

\section{Conclusões}

O propósito do aplicativo Tem Açúcar? revelou atrair o engajamento de usuários que, de fato, justificam sua motivação em nome da redução do consumo e da promoção de colaboração e confiança entre vizinhos. Além da defesa desses valores, e da própria adesão ao aplicativo, o princípio da dádiva se viu presente em situações específicas. Uma delas é a maior motivação que alguns usuários relataram em emprestar do que em pedir emprestado, revelando a orientação de comportamentos desinteressados e não utilitaristas. 
Os princípios da dádiva também se fazem presentes nos gestos daqueles que criam formas de retribuir o empréstimo que lhes foi feito, como com dicas de viagem, contatos profissionais, convites para eventos sociais, bilhetes de agradecimento, roteiros de turismo, um bolinho, uma bandeira ou ainda um livro.

Em suma, é adequado afirmar que a reciprocidade é presente nas transações promovidas a partir do aplicativo Tem Açúcar? e, embora não relatada, a sensação de terem contraído uma "dívida" ou uma obrigação por retribuir de modo simultaneamente voluntário e obrigatório, parece fazer parte das interações.

Os usuários afirmam que dificilmente emprestariam objetos pessoais, com valor afetivo e financeiro altos e objetos de uso profissional ou frágeis, isto é, não estariam dispostos a emprestar coisas pessoais insubstituíveis, seja emocionalmente, seja financeiramente. Apesar disso, foi ampla a gama de produtos narrados como tendo circulado por meio do aplicativo: mochila, pneu, lente de câmera, máquina de cartão, itens para gatos, livros de design, fritadeira, equipamento de mergulho, mesa de costura, entre outros.

A confiança é um fator essencial para a materialização das trocas e sua construção é dependente definitivamente de dois elementos: reputação do usuário e comentários deixados por terceiros no perfil do usuário. Esses dois elementos são decisivos para as tomadas de decisão que acompanham uma troca, doação ou empréstimo e influenciam também a logística do encontro para a materialização da transação, seja ela da natureza que for. Isso significa que encontros para transação podem ser agendados em locais públicos e trocas podem ser feitas sem que os usuários sequer se encontrem, a depender dos dois elementos supracitados e da consequente confiança de um usuário em outro.

Com relação à formação de laços entre os usuários, é preciso situar o aplicativo dentro das modalidades interativas que marcam a sociedade contemporânea, já definidas por suas "conexões em rede" (Castells, 1998) e por sua natureza "líquida" (Bauman, 1998) -em detrimento de vínculos fortes, presenciais e estáveis. Assim, sob esse paradigma, o aplicativo Tem Açúcar? pode ser entendido como um dispositivo que, de fato, engendra laços sociais, laços esses reveladores da natureza própria de seu tempo: frágeis, virtuais e transitórios.

Para pensar criticamente no potencial de ação do aplicativo no Rio de Janeiro, não se pode deixar de lado as limitações dadas pelas próprias condições de operar o dispositivo, que excluem uma parte dos habitantes da cidade: possuir aparelho celular, com acesso à Internet, ter domínio das instruções do Tem Açúcar? e dos demais aplicativos indiretamente associados a ele, como Whatsapp e Facebook. Sob essa perspectiva, é possível qualificar o perfil dos usuários pesquisados como seletivo, já que apresentam elevada escolarização 
e habitam em bairros privilegiados. A localização, por certo, é um fator que tanto potencializa quanto limita os efeitos do aplicativo, já que a proximidade geográfica é condição sine qua non das interações geradas por meio dele.

\section{Referências bibliográficas}

Acquier, A.; Daudigeos, T.; Pinkse, J., (2017). Promises and paradoxes of the sharing economy: an organizing framework. Technological Forecasting \& Social Change. https:// doi.org/10.1016/j.techfore.2017.07.006

Anduiza, E.; Cantijoch, M. \& Gallego, A. (2009). Political participation and the internet. Information, Communication \& Society, 12: 6, 860-878. https://doi.org/10.1080/13691180802282720

Arnold-Chatalifaud, M.; Thumala, D.; Urquiza, A. (2007). Colaboración, cultura y desarrollo: entre el individualismo y la solidaridad organizada. In: Colaboración, cultura y desarrollo. Santiago: Universidad de Chile/Fundacion Sóles. p.15-34.

Autosustentável - Tem Açúcar? Plataforma incentiva empréstimo entre vizinhos e evita o desperdício. Disponível em: http://autossustentavel.com/2017/10/temacucar-plataforma-incentiva-emprestimos-vizinhos.html - Acesso dia $31 / 08 / 2018$

Barbrook, R. (1998). The Hi-Tech Gift Economy. First Monday, v. 3, n. 12, February.

Bauman, Z. (1998). O mal-estar da pós-modernidade. Rio de Janeiro: Jorge Zahar.

Belk, R. (2010). Sharing. Journal of Consumer Research, 36, 715-734. https://doi.org/10.1086/612649

Belk, R. (2014). You are what you can access: Sharing and collaborative consumption online. Journal of Business Research, v. 67, n. 8, p. 1595-1600, 2014. https://doi.org/10.1016/j.jbusres.2013.10.001

Bennett, W. \& Segerberg, A. (2011). Digital Media and the Personalization of Collective Action, Information, Communication \& Society, 14:6, 770-799. Disponível em: http://wwww.tandfonline.com/doi.org/10.1080/1369118X.2011.579141

Bergquist M. \& Ljungberg J. (2001). The power of gifts: organizing social relationships in open source communities. Information Systems Journal, v. 11, n. 4, pp. 305320. https://doi.org/10.1046/j.1365-2575.2001.00111.x

Botsman, R. \& Rogers, R. (2011). O que é meu é seu: como o consumo colaborativo vai mudar o nosso mundo. Porto Alegre: Bookman.

Caillé, A. (1998). Nem holismo nem individualismo metodológico: Marcel Mauss e o paradigma da dádiva. Revista Brasileira de Ciências Sociais. São Paulo, v. 13, n. 8. http://dx.doi.org/10.1590/S0102-69091998000300001

Castañeda, M. (2015). Political mobilization by e-mail: an analysis of Avaaz as an actornetwork. Revista Compolítica, v.5, n.1, p.31-56. https://doi.org/10.21878/compolitica.2015.5.1.77

Castells, M. (1999). A sociedade em rede. São Paulo, Paz e Terra.

Castells, M. (2003). A galáxia da Internet: reflexões sobre a Internet, os negócios e a sociedade. Rio de Janeiro: Jorge Zahar Ed.

Chan, N.; Walker, C. \& Gleaves, A. (2015). An Exploration of Students' Lived Experiences of Using Smartphones in Diverse Learning Contexts Using a Hermeneutic Phenomenological Approach. Computers and Education 82: 96106. 
Galehbakhtiari, S.; Tahmours, H. (2015). A Hermeneutic Phenomenological Study of Online Community Participation: Applications of Fuzzy Cognitive Maps. Computers in Human Behavior 48: 637- 643.

Ghaffari, K.; Lagzian; M. (2018) Exploring users' experiences of using personal cloud storage services: a phenomenological study. Behaviour \& Information Technology, 37:3, 295-309. https://doi.org/10.1080/0144929X.2018.1435722

Godbout, J.T. (1998). Introdução à dádiva. Revista Brasileira de Ciências Sociais, 13(38),39-52.https://dx.doi.org/10.1590/S0102-69091998000300002

Hamari, J., Sjöklint, M. \& Ukkonen, A. (2016). The Sharing Economy: Why People Participate in Collaborative Consumption. American Society for Information Science and Technology. Journal, 67(9), 2047-2059. https://doi.org/10.1002/asi.23552

Harvey, J; Smith, A. \& Golightly, D. (2014). Giving and sharing in the computermediated economy. Journal of Consumer Behavior, 14(5), 1479-1487.

Heylighen, F. (2016). Towards an intelligent network for matching offer and demand: from the sharing economy to the global brain. Technological Forecasting \& Social Change. http://dx.doi. org/10.1016/j.techfore.2016.02.004

Hypeness. (2015). Economia Colaborativa: ela quer te ajudar a economizar, faturar e restaurar sua fé na humanidade - Disponível em: https://www.hypeness.com.br/2015/05/economia-colaborativa-como-o-sensode-comunidade/ - Acesso em 05/08/2018

Latour, B. (2005). Reassembling the Social - An Introduction to Actor--NetworkTheory. Oxford.

Madsbjerg, Christian. (2017). Sensemaking. The power of the Humanities in the Age of the Algorithm. Hachette Books.

Malinowski, B. (1976). Argonautas do pacífico ocidental: um relato do empreendimento e da aventura dos nativos nos arquipélagos da Nova Guiné melanésia [1922]. São Paulo: Abril Cultural.

Martins, P. H. (2008). De Lévi-Strauss a Mauss - Movimento Anti-Utilitarista nas Ciências Sociais: itinerários do dom. Revista Brasileira de Ciências Sociais. São Paulo, v.23, n.66, p.105 129. http://dx.doi.org/10.1590/S010269092008000100007

Martins, P. H. (2010). Redes sociais como novo marco interpretativo das mobilizações coletivas contemporâneas. Cad. CRH [online] vol.23, n.59, pp.401-418. http://dx.doi.org/10.1590/S0103-49792010000200013

Mauss, M. (2003) Ensaio sobre a dádiva: forma e razão da troca nas sociedades arcaicas [1925]. Sociologia e Antropologia. São Paulo: Cosac \& Naify. p.185-314.

Möhlmann, M. (2015). Digital Trust and Peer-to-Peer Collaborative Consumption Platforms: A Mediation Analysis. SSRN Electronic Journal. December. DOI: $10.2139 /$ ssrn.2813367

O Globo. (2015). Tem açúcar com 22 mil usuários, site brasileiro promove empréstimos entre vizinhos. Disponível em: https://oglobo.globo.com/sociedade/tecnologia/tem-acucar-com-22-milusuarios-site-brasileiro-promove-emprestimos-entre-vizinhos-15246520 Acesso em 04/04/2018.

Park, R. (1915). The city: suggestions for the investigation of human behavior. The American Journal of Sociology. V.20, n.5. Disponível em: https://www.journals.uchicago.edu/doi/pdfplus/10.1086/212433

Redbull. (2019). Tem Açúcar - I am the Engine S01 - E09. Disponível em: https://www.redbull.com/int-en/episodes/i-am-the-engine-s1-e9-tem- 
acucar?fbclid=IwAR06SVwNdyvPMvAsmWolF3EOk9iyANcnWH8Ydu4WQ70IafcLQ 75ALmfviQw. Acesso em: 22 fev 2020.

Saraswat, S. (2012). A Phenomenological Investigation of Information and Communications Technology at a Public Sector Enterprise in India. Journal of Global Information Technology Management 15 (4): 43-63.

Simmel, G. (2005). As grandes cidades e a vida do espírito [1903]. Revista Mana, v.11, n.2, Rio de Janeiro. http://dx.doi.org/10.1590/S0104-93132005000200010

Smith, J. (2004). Reflecting on the Development of Interpretative Phenomenological Analysis and Its Contribution to Qualitative Research in Psychology. Qualitative Research in Psychology 1 (1): 39-54.

Soares, C.; Joia, L.; Altieri, D. \& Regasso, J. (2019). Sistema de mensagens instantâneas e o movimento de caminhoneiros no Brasil: uma análise sob a ótica da Teoria AtorRede. In: XLIII Encontro da ANPAD - EnANPAD 2019, São Paulo, 02-05 outubro.

Stalder, F. (2005). Open Cultures and the Nature of Networks, Revolver Books, Frankfurt/Main.

Sundararajan, A. (2016). The sharing economy. The end of employment and the rise of crowd-based capitalism. Cambridge, MA: MIT Press.

Sutherland, W. \& Jarrahi, M. (2018). The Sharing Economy and Digital Platforms: A Review and Research Agenda. International Journal of Information Management, 43, 328-341.

Symeonides, R. \& Carrie, C. (2015). The Personal Experience of Online Learning: An Interpretative Phenomenological Analysis. Computers in Human Behavior 51: 539-545.

Tarrow, S. (2005). The new transnational activism. New York: Cambridge University Press. Wirth, L. (1938). Urbanism as a Way of Life. American Journal of Sociology 44 (July): 3-24. https://doi.org/10.1177/004912417200100203

Este artículo es de acceso abierto. Los usuarios pueden leer, descargar, distribuir, imprimir y enlazar al texto completo, siempre y cuando sea sin fines de lucro y se cite la fuente.

\section{CÓMO CITAR ESTE ARTÍCULO:}

Da Silva Caldas Brito, N. y Rodriguez Goia, M. (2020). Uma rede sociotécnica à luz do paradigma da dádiva: análise do aplicativo de empréstimo de objetos Tem Açúcar? no Rio de Janeiro. Paakat: Revista de Tecnología y Sociedad, 10(18). http://dx.doi.org/10.32870/Pk.a10n18.472

\footnotetext{
* Mestre em Gestão Empresarial pela Escola Brasileira de Administração Pública e de Empresas da Fundação Getúlio Vargas (EBAPE/FGV), Graduada em Comunicação Social pela Universidade Veiga de Almeida (2005). ORCID: https://orcid.org/0000-0003-1130-4563/print natalia.caldas@gmail.com

** Doutora em Antropologia Urbana pela Universitat Rovira i Virgili (Catalunha, Espanha), Mestre em Sociologia e Antropologia pela Universidade Federal do Rio de Janeiro (UFRJ). Professora da Escola Brasileira de Administração Pública e de Empresas da Fundação Getúlio Vargas (EBAPE/FGV). ORCID: http://orcid.org/0000-0001-8733-7885 marisol.goia@gmail.com
} 